\title{
Health system factors associated with choice of place of delivery among postnatal women in Marsabit County, Kenya
}

\author{
Christine Bokayo Arero, $\mathrm{MPH}^{1}$, Keraka Nyanchoka Margaret, $\mathrm{PhD}$ (Professor) ${ }^{2}$, Shadrack Yonge Ayieko, $\mathrm{PhD}^{3}$, \\ Matoke Omwenga Vincent, $\mathrm{MPH}^{4}$, Okari Maseme Geoffrey, $\mathrm{MSc}^{5}$ \\ ${ }^{I}$ Kenyatta University, Department of Population, Reproductive Health and Community Resource Management, School of Public \\ Health and Applied Human Sciences, Kenyatta University, Nairobi Kenya \\ ${ }^{2}$ Department of Population, Reproductive Health and Community Resource Management, School of Public Health and Applied \\ Human Sciences, Kenyatta University, Nairobi Kenya \\ ${ }^{3}$ Department of Environmental and Health Sciences, School of Applied and Health Sciences, Technical University of Mombasa, \\ Mombasa Kenya \\ ${ }^{4}$ Department of Population, Reproductive Health and Community Resource Management, Kenyatta University, Nairobi Kenya \\ ${ }^{5}$ Department of Health Management and Informatics, Kenyatta University, Nairobi Kenya
}

\begin{abstract}
:
Background: Worldwide, there were approximately 295,000 women died as a result of pregnancy and childbirth related complications in 2017. Majority of this was from Sub-Saharan Africa with 196000. In Africa, about seventy-five per cent maternal and neonatal deaths occur outside health facilities. In Kenya, maternal mortality rate is 362 per 100,000 live births with $61.2 \%$ deliveries occurring in hospitals. There is still evidence of home deliveries despite significant efforts through several interventions.
\end{abstract}

Objective: The study aims to determine health system factors associated with choice of place of delivery among postnatal women in Marsabit County, Kenya.

Materials and methods: This research adopted a mixed descriptive cross-sectional study design method. Quantitative and qualitative research methods were used to collect data from participants. A total of $\mathbf{4 1 6}$ respondents were interviewed. The respondents were drawn from households using systematic random sampling at a predetermined interval of four. The study was done in 24 selected villages from Moyale Township, Golbo, Dukana and North-Horr Wards. Statistical Package for Social Sciences (SPSS) version 20.0 was used to analyze descriptive data. Inferential statistics such as Chi-Square tests at $95 \%$ confidence level and p-values of 0.05 was used to determine variable association.

Results: About 178(43.3\%) of postnatal women delivered at home in Marsabit County. Chi-square statistics indicated that most health system factors such as distance to the nearest facility $(p=0.001)$, experience with care provider $(0.012)$, hindrance from health facility $(p=0.008)$ and provision of information $(0.001)$ were associated with choice of place of delivery. Results from focused group interviews and key informants were reported as direct narrations.

Conclusion: The study concluded that there was a significant number of women who are still delivering at home in Marsabit County. Majority of the health system factors were associated with choice of place of delivery. This requires concerted efforts by relevant stakeholders to ensure improved access health facility delivery through mobile clinics to assist women deliver under the hands of skilled birth attendants thus discouraging home deliveries.

Key Words: Health system, Place of delivery, Postnatal Women.

\section{INTRODUCTION}

$\mathrm{W}$ orldwide, there were approximately 295,000 women died as a result of pregnancy and childbirth related complications in 2017. Majority of this was from Sub-Saharan Africa with $196000^{1}$. In Africa, about seventy-five per cent maternal and neonatal deaths occur outside health facilities. In Kenya, maternal mortality rate is 362 per 100,000 live births with $61.2 \%$ deliveries occurring in hospitals ${ }^{2}$. There is still evidence of home deliveries despite the high risks and significant efforts through several health interventions ${ }^{3}$.

There has been reported progress by the Kenyan Government towards achieving the WHO target of 147 maternal deaths per 100,000 live births ${ }^{4}$. Marsabit County is among the top ten counties with highest maternal mortality rate standing at $1127 / 100,000^{1}$. May policies and interventions have been put up to ensure all deliveries are attended by skilled birth attendants in hospital settings 5 . These interventions include Universal Health Coverage, free maternal delivery using Linda Mama Insurance cover, maternal shelter, beyond zero campaigns and Output Based Approach (OBA) to provide subsidies to ensure safe motherhood ${ }^{3}$.

However, despite all these interventions playing a significant role, there is still evidence of home delivery ${ }^{6}$. This has led to establishment of Community Based Referral Systems (CBRS) by through Traditional Birth Attendants converted to community-based referral agents, community health volunteers and provision of mother pack incentives. Strengthening community health care systems is essential to accessing skilled delivery services at health facilities through 
effective community referral systems ${ }^{7}$. The strategy of using community based referral agents includes identification of traditional birth attendants (TBAs) from each sub-location. They are trained on their role as referral agents, identifying danger signs of pregnancy and risk factors associated with home deliveries.

\section{LITERATURE REVIEW}

\subsection{Introduction}

Globally Maternal mortality is unacceptably high. It is estimated that every day, about 810 women die from preventable causes related to pregnancy and childbirth with developing countries accounting for 99\% of such maternal deaths $^{8}$. It was estimated that in 2015, roughly 303000 women died during and following pregnancy and childbirth ${ }^{9}$. Sub-Saharan Africa and South Asia account for 88 per cent of maternal deaths worldwide.

Sub-Saharan Africans suffer from the highest maternal mortality ratio - 546 maternal deaths per 100,000 live births, or 201,000 maternal deaths a year. This is two thirds $(66 \%)$ of all maternal deaths per year worldwide. South Asia follows with 66,000 maternal deaths a year, accounting for 22 per cent of the global total. Furthermore, regional and global averages tend to mask large disparities both within and between countries ${ }^{1}$. It has been revealed that skilled care before, during and after childbirth can save the lives of women and newborn babies. Between 2016 and 2030, as part of the Sustainable Development Goals, the target was to reduce the global maternal mortality ratio to less than $70 / 100000$ live births ${ }^{10}$.

In Addis Ababa for instance, the capital of Ethiopia, though the private health facilities (hospitals and clinics) outnumber public clinics, only $20 \%$ of deliveries take place in the private sectors and $17 \%$ of mothers deliver at home ${ }^{11}$. Findings from a study in Nigeria showed that $60.8 \%$ of the pregnant women had their last delivery at home ${ }^{12}$ which is similar although a bit lower than what was found in the rural area of Zambia where home delivery was about $67 \%$.

\subsection{Health system factors influencing the choice of delivery}

Health system factors have been noted to influence the uptake of health care services such as antenatal care and delivery with the help of skilled birth attendants. The patients' perception concerning the quality of service provision is very important as it influences their health outcomes. Provision of services which meet the needs, wishes and expectations of women ensures they seek health care services from health care delivery systems whenever they require such services ${ }^{14}$. A study in India revealed that women who felt dissatisfied with services at the health facility did not continue with their antenatal care services as required ${ }^{15}$.

Unfriendly health care providers instill a negative attitude of pregnant women towards services. Dehumanizing, devaluing and disempowering experiences lead to perceived challenge to personal identity and undermines self-sensing affecting service delivery. Choosing to deliver at home is associated with concerns about the quality of services prompting women to shy from hospitals ${ }^{16}$. Good handling of patients means they can seek subsequent services in the health facilities thus more hospital deliveries. Mistreatment of women during delivery has been noted as factor that affected hospital delivery among pregnant women in Nigeria ${ }^{17}$.

Healthcare providers should listen to clients' concerns, give reliable advice, and provide full and accurate information. Information empowers women to make informed decisions on the most appropriate place of delivery ${ }^{18}$. Healthcare providers should explain the importance of antenatal care to pregnant mothers and hospital delivery in preventing maternal and neonatal mortalities ${ }^{19}$. Perceived support from care providers during service delivery improves outcomes and overall women's satisfaction with care ${ }^{20}$. Perceived potential behavior and reception from the healthcare staff was an issue in Serra Leone that significantly influenced hospital delivery ${ }^{21}$. In a qualitative study done in Tanzania, most people preferred to deliver at private hospitals and/or at home because they reported bad reception at government facilities ${ }^{22}$.

In rural areas, people are forced to walk or travel long distances to access the health facility of which many have been reported to be providing poor quality services. In some areas roads are not in good condition and there is limited number of vehicles operating through such routes. This further harder for the women to reach the hospital to delivery making some to deliver on the way even when they had an intention of delivering at the hospital ${ }^{23}$. Distance to the nearest health care center was reported to be one of the reasons that made women to deliver at home. Study findings from Ethiopia revealed that distance was associated with home deliveries ${ }^{24}$. In Ghana, the average distance to the nearest health facility was 4.7 kilometers ${ }^{25}$. Long distances and poor road networks has been associated with low hospital deliveries among pastoralist women in Kenya ${ }^{26}$.

The cost of service deliver and the physical ambiance of the health facilities may act as a major hindrance to hospital deliveries. According to a study done in ethnic minority villages of Lao, it was extremely expensive to access hospital delivery services ${ }^{27}$. According to other studies, women deliver at home to avoid the costs incurred in hospital delivery ${ }^{26}$. The indirect costs associated with hospital deliveries in remote areas of Sierra Leone were high hence opting for home deliveries $^{21}$. Friendly structures coupled organized channels of service delivery means pregnant women can easily access services without struggles. In Northwest Ethiopia, ease of access to hospital infrastructure affected choice of place of delivery ${ }^{28}$.

\section{MATERIALS AND METHODS}

\subsection{Study design}

The study employed a mixed descriptive cross-sectional study design to establish the health system factors associated with choice of place of delivery among postnatal women in Marsabit County, Kenya. 


\section{2 study setting}

The study was conducted in Marsabit County. Marsabit County is among the counties with highest maternal deaths in the country and community based referral systems and mother pack incentives have been implemented. The county has a population of 291,166 with $52 \%$ male and $48 \%$ female covering 70,961.2 Sq. $\mathrm{KM}^{29}$. The county has four subcounties namely; North Horr, Laisamis, Saku and Moyale. The study was specifically conducted in Moyale and North Horr sub-counties. Moyale sub-county has 7 wards while North Horr sub-county has 5 wards. The County has 56,941 households $^{29}$. It has 2 district hospitals, 6 health centres and 34 dispensaries. The rate of maternal mortality is 1127 per 100,000 live births. The ratio of doctor-population and nursepopulation is $15: 100,000$ and $91: 100,000$ respectively. Facility deliveries are at $44.4 \%$ against $61.2 \%$ of the national average $^{30}$.

\section{3 study population}

The study was conducted in Marsabit County. Marsabit County is among the counties with highest maternal deaths in the country and community based referral systems and mother pack incentives have been implemented. The county has a population of 291,166 with $52 \%$ male and $48 \%$ female covering 70,961.2 Sq. $\mathrm{KM}^{29}$. The county has four subcounties namely; North Horr, Laisamis, Saku and Moyale. The study was specifically conducted in Moyale and North Horr sub-counties. Moyale sub-county has 7 wards while North Horr sub-county has 5 wards. The County has 56,941 households $^{29}$. It has 2 district hospitals, 6 health centres and 34 dispensaries. The rate of maternal mortality is 1127 per 100,000 live births. The ratio of doctor-population and nursepopulation is $15: 100,000$ and $91: 100,000$ respectively. Facility deliveries are at $44.4 \%$ against $61.2 \%$ of the national average $^{30}$.

\subsection{Sampling techniques}

Marsabit County was purposively selected because it records one of the highest maternal deaths in the country (the fourth high burden county in the country) and in which the community based referral systems and mother pack incentives have been implemented. Moyale and North Horr sub-counties were randomly selected from folded pieces of paper. From Moyale sub-county, Moyale Township Ward (3 sub-locations) which is most urban and populous and Golbo Ward (7 sublocations) which is most rural was selected. In North Horr sub-county, North Horr Ward (5 sub-locations) which is most populous and most urban, and Dukana Ward (4 sub-locations) which is most rural was selected. Two sub-locations from each ward selected were were randomly sampled for study. Respondents for interview were drawn from households' selected using systematic random sampling at a predetermined interval of four. Every 4th household with a postnatal woman who had delivered a child within one month prior to the conduct of the study was interviewed until the required number of participants in each sub-location is reached. The respondents selected for the study were proportional to the number of postnatal women in each sub-location. In order to obtain additional information, 4 Focused Group Discussions (FGD) were held by the researcher with postnatal women. The FGDs comprised of 9 participants selected purposively based on their ability to give the required information. In addition, 20 Key Informant Interviewees (KII) were purposively selected to give their views on the study topic. The researcher involved Community Based Referral Agents from Marsabit County as the key informants (See table 3.1)

Table 3.1: Proportion of respondents for selection

\begin{tabular}{|c|c|c|c|c|}
\hline $\begin{array}{c}\text { Sub- } \\
\text { county }\end{array}$ & Wards & $\begin{array}{c}\begin{array}{c}\text { Sub- } \\
\text { locations }\end{array} \\
\end{array}$ & $\begin{array}{c}\text { Total } \\
\text { HH } \\
\end{array}$ & Sampled HH \\
\hline \multirow{4}{*}{ Moyale } & \multirow[b]{2}{*}{$\begin{array}{l}\text { Moyale } \\
\text { Township }\end{array}$} & Township & 365 & 82 \\
\hline & & $\begin{array}{c}\text { Ngurumes } \\
\mathrm{a} \\
\end{array}$ & 281 & 63 \\
\hline & \multirow[b]{2}{*}{ Golbo } & Golla & 224 & 50 \\
\hline & & Funyatta & 273 & 61 \\
\hline \multirow{4}{*}{$\begin{array}{l}\text { North } \\
\text { Horr }\end{array}$} & \multirow[b]{2}{*}{ Dukana } & Balesa & 241 & 54 \\
\hline & & Sabare & 198 & 44 \\
\hline & \multirow[b]{2}{*}{ North Horr } & Gallas & 119 & 27 \\
\hline & & Malabot & 156 & 35 \\
\hline Total & & & 1857 & 416 \\
\hline
\end{tabular}

Source: Marsabit County Development Plan, (2016).

\subsection{Sample size determination}

Sample size was determined using Fishers' formula of 1998 for populations more than $10,000^{31}$. Sample size:

$\mathrm{n}=\underline{\mathrm{z}^{2} \mathrm{pq}}$

$\mathrm{d}^{2}$

Where: $\mathrm{n}=$ desired sample size

$\mathrm{z}=$ standard normal deviate (1.96)

$\mathrm{p}=0.44$ proportion of women with hospital deliveries in Marsabit County (MoH, 2018).

$\mathrm{q}=1-\mathrm{p}=1-0.44=0.54$ Assumed proportion not delivering in health facilities.

interval

$\mathrm{d}=$ degree of accuracy (0.05) i.e. at $95 \%$ confidence

When substituted the sample size was 378 and to cater for non-responses the researcher $10 \%$ (38) of subjects were added to cater for non-responses thus 416 questionnaires were administered.

\subsection{Data collection techniques}

Quantitative data was collected using semi-structured research questionnaires. The questionnaires were administered in English and translated to Kiswahili and other local languages as deemed necessary to ensure they are understood by the respondents. Trained research assistants administered the questionnaires to the participants and guided them to fill in 
their responses. They were monitored, guided and supervised by the researcher. All collected questionnaires were kept in locked cabinets throughout the study period and accessed by the researcher only to ensure confidentiality and avoid data loss.

Qualitative data were obtained from focused group discussions held with primary respondents in four FGD sessions. The FGD sessions were carried out in a room within the locational Headquarter offices. The sessions were moderated by the researcher with the research assistants recording their audio views and notes taken. This encouraged free discussion among participants thus captures information which may not be achievable in a one on one interview. The researcher also conducted key informant interviews with 20 community referral agents in private offices within the Locational headquarters of the selected locations to supplement information obtained from primary respondents. Their views, opinions and suggestions will be taken into account.

\subsection{Data management and analysis approach}

Quantitative data was entered and stored in Microsoft Excel program. Data cleaning and editing was done where extreme, missing and inconsistent values were identified and corrected. Coding and verification of the data was done for easy manipulation, analysis and presentation. Data was then exported to Statistical Package for Social Sciences (SPSS) software version 20.0 for analysis. Descriptive analysis was presented in form of percentages, frequency tables, charts and graphs.

Inferential statistics were computed using Pearson's Chisquare Tests presented in cross tabulations. This was done at 95\% confidence interval and p-values of less than 0.05 were considered significant in testing the association between study variables. Qualitative data from the FGDs and KII were presented as direct quotes or narrations and triangulated to validate and enrich the quantitative findings.

\subsection{Ethical considerations}

The researcher sought approval from Kenyatta University Graduate School. The study obtained ethical clearance from Kenyatta University Ethics and Review committee. A research permit was obtained from the National Council for Science, Technology and Innovation (NACOSTI). Research authorization was sought from Marsabit County Commissioner, County Director of Education and County Director of Health Services. Permission was also sought from the local administration units. The study obtained informed consent from research participants before they were interviewed. The purpose of the study was clearly explained and participants informed that their involvement in the research was voluntary without due coercion or influence. Their identities were kept private and confidential and the collected information used only for the purpose of this study only. The findings of this research would be presented to Kenyatta University, Marsabit County and the National
Commission for Science, Technology and Innovation. These results would also be published for reference and presented in conferences and workshops of relevant stakeholders.

\section{RESULTS}

\subsection{Choice of place of delivery}

\subsubsection{Proportion of respondents with respect to place of delivery}

The results showed that more than half $233(56.7 \%)$ of the respondents delivered at the hospital while the rest 178 $(43.3 \%)$ delivered at home. The results were as shown in figure 4.1. The qualitative results established that indeed women preferred delivering at home through the help of traditional birth attendants whom they were familiar with. One focused group discussant said,

“...you know these women helping us in delivery are the people from our community who have been with us for long and they have the experience and respect from all of us. So that's why I prefer them to the hospital where I don't know the doctors or nurses and thus, I will not be free with them. I have heard from my neighbor that at the hospital you are shouted at and sometimes insulted by those medics..."

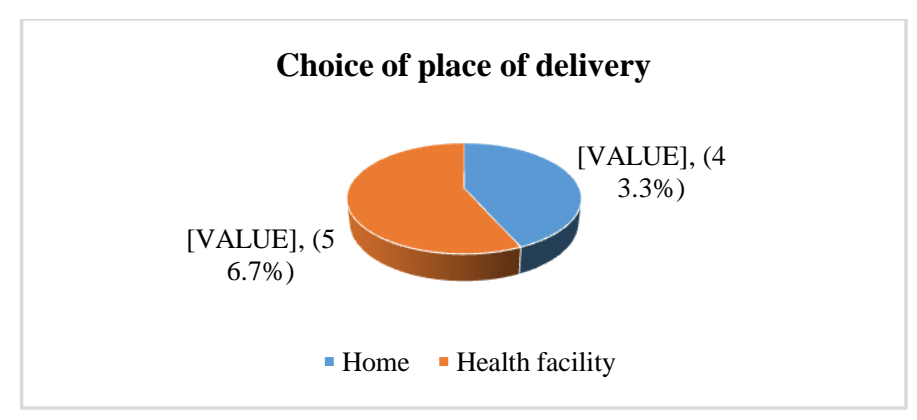

Fig 4.1: Choice of place of delivery among respondents

\subsubsection{Reasons for home delivery}

Results revealed that $75(42.1 \%)$ of the respondents reported instant labor pains as the main reason for home delivery followed by $51(28.6 \%)$ who delivered at home just because their previous deliveries were at home. Results were as shown in figure 4.2 below:

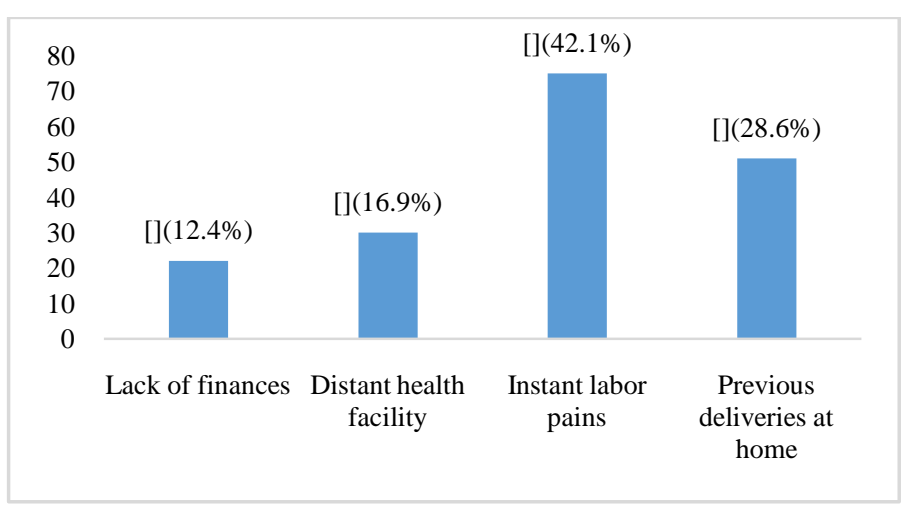

Fig 4.2: Reasons for home delivery among respondents 


\subsubsection{Reasons for hospital delivery}

The results revealed that $100(42.9 \%)$ of respondents delivered at the hospital because of the perceived quality of services followed by $93(39.9 \%)$ who feared complications. The results were as presented in table 4.1. One of the discussants during focused group discussion session said;

"...delivering at home can be risky. Imagine you get complication while delivering at home at night yet the hospital is very far from here? So that is my main worry which makes me deliver in the hands of trained health care worker. My cousin lost her child because of complications when she was delivering at home. So, it's better to always take precautions..." (FGD Discussant).

Table 4.1: Reasons for health facility delivery among respondents $(n=233)$

\begin{tabular}{|c|c|c|}
\hline $\begin{array}{c}\text { Reasons for health facility } \\
\text { delivery }\end{array}$ & Frequency (N) & $\begin{array}{c}\text { Percentage } \\
(\mathbf{\%})\end{array}$ \\
\hline Fear of complications & 93 & 39.9 \\
\hline Quality health services & 100 & 42.9 \\
\hline Referral & 17 & 7.3 \\
\hline Health facility is near & 15 & 6.4 \\
\hline Spouse recommended & 8 & 3.4 \\
\hline
\end{tabular}

\subsubsection{Assistance during delivery}

Majority $241(58.6 \%)$ of the respondents reported that they delivered under the assistance of the health care provider followed by $136(33.1 \%)$ who delivered with the help of the traditional birth attendant. The results were as shown in the figure 4.3 below:

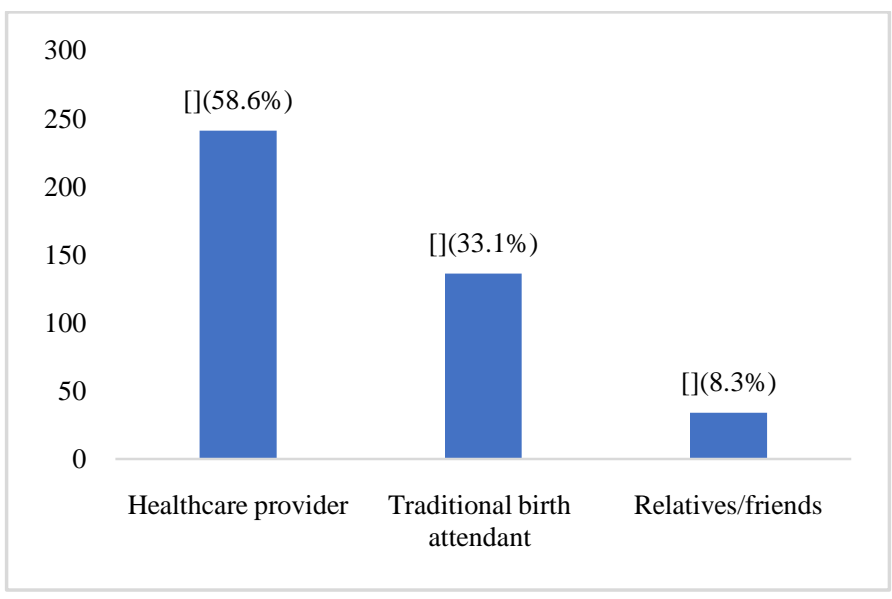

Fig 4.3: Person who assisted during delivery

\subsection{Health facility factors and choice of place of delivery}

\subsubsection{Health facility factors}

The study revealed that less than a half $164(39.9 \%)$ of the respondents approximated the distance to the nearest health facility to more than 4 kilometers. Slightly more than a third $164(39.9 \%)$ of the respondents perceived the cost of accessing hospital delivery to be free. Regarding hindrances to hospital delivery, the results showed that $170(41.4 \%)$ of the respondents would not deliver at the facility because of distance. More than half $238(57.9 \%)$ of the respondents had a good experience with care providers during service delivery.

Regarding the ease of access to buildings and physical structures, results showed that most 305 (74.2\%) of the respondents accessed the structures with ease while the rest $106(25.8 \%)$ did not. The results showed that most 329 $(80.0 \%)$ liked the perceived quality of services while the rest $82(20.0 \%)$ did not like. Further results showed that 343 $(83.5 \%)$ of the respondents were given information before and after services while the rest 68 (16.5\%) were not given. Results were as presented in table 4.2 below:

Table 4.2: Distribution of health facility factors among respondents $(n=411)$

\begin{tabular}{|c|c|c|c|}
\hline Variable & $\begin{array}{c}\text { Respondent } \\
\text { response }\end{array}$ & $\begin{array}{l}\text { Frequency } \\
\text { (N) }\end{array}$ & $\begin{array}{c}\text { Percentage } \\
(\%)\end{array}$ \\
\hline \multirow{3}{*}{$\begin{array}{l}\text { Approximate distance } \\
\text { to the nearest health } \\
\text { facility }\end{array}$} & Less than $1 \mathrm{KM}$ & 104 & 25.3 \\
\hline & $2-3 \mathrm{KM}$ & 143 & 34.8 \\
\hline & Over $4 \mathrm{KM}$ & 164 & 39.9 \\
\hline \multirow{5}{*}{$\begin{array}{c}\text { Perceived cost } \\
\text { associated with hospital } \\
\text { delivery }\end{array}$} & None/free & 164 & 39.9 \\
\hline & $1-99$ & 25 & 6.1 \\
\hline & $100-199$ & 41 & 10.0 \\
\hline & $200-299$ & 74 & 18.0 \\
\hline & $\geq 300$ & 107 & 26.0 \\
\hline \multirow{6}{*}{$\begin{array}{l}\text { Hindrances from } \\
\text { delivery in health } \\
\text { facility }\end{array}$} & Lack equipment & 59 & 14.4 \\
\hline & $\begin{array}{l}\text { Lack enough } \\
\text { finances }\end{array}$ & 33 & 8.0 \\
\hline & $\begin{array}{l}\text { Poor provider } \\
\text { attitude }\end{array}$ & 42 & 10.2 \\
\hline & $\begin{array}{c}\text { Poor quality of } \\
\text { services }\end{array}$ & 33 & 8.0 \\
\hline & $\begin{array}{c}\text { Distant health } \\
\text { facility }\end{array}$ & 170 & 41.4 \\
\hline & No hindrance & 74 & 18.0 \\
\hline \multirow{3}{*}{$\begin{array}{l}\text { Experience with care } \\
\text { providers during } \\
\text { service delivery }\end{array}$} & Good & 238 & 57.9 \\
\hline & Fair & 115 & 28.0 \\
\hline & Poor & 58 & 14.1 \\
\hline \multirow{2}{*}{$\begin{array}{c}\text { Easier to access } \\
\text { buildings and physical } \\
\text { structures }\end{array}$} & Yes & 305 & 74.2 \\
\hline & No & 106 & 25.8 \\
\hline \multirow{2}{*}{$\begin{array}{l}\text { Liked the quality of } \\
\text { services received }\end{array}$} & Yes & 329 & 80.0 \\
\hline & No & 82 & 20.0 \\
\hline \multirow{2}{*}{$\begin{array}{l}\text { Given information } \\
\text { before and after } \\
\text { services }\end{array}$} & Yes & 343 & 83.5 \\
\hline & No & 68 & 16.5 \\
\hline
\end{tabular}

4.2.2 Health facility factors associated with choice of place of delivery

The results revealed that less than a half $77(43.3 \%)$ of the respondents whose approximate distance to the health facility was more than 4 kilometers delivered at home. There was a significant statistical association between distance to the nearest facility and choice of place of delivery $(p=0.001)$. Less than a half $115(49.3 \%)$ of respondents who felt it would be free to access delivery services delivered at the hospital. 
There was no association between cost of accessing delivery services and choice of place of delivery $(\mathrm{p}=0.053)$. Most 110 $(61.8 \%)$ of the respondents delivered at home due to distant health facilities. There was a significant statistical association between hindrances to delivery at the facility and choice of place of delivery $(\mathrm{p}=0.008)$. Most $137(58.8 \%)$ of the respondents who had a prior good experience with health care providers delivered at the hospital. Experience with health services providers significantly influenced choice of place of delivery $(\mathrm{p}=0.012)$. The results revealed that $161(90.4 \%)$ of the respondents who delivered at home had liked the quality of services. There was no statistically significant association between liking the quality of services one received and choice of place of delivery among the respondents $(p=0.091)$. However, results from qualitative data disagreed with quantitative data as women felt that the perceived quality of services was not good. During a FGD session, a woman revealed,
“... I went to the hospital when my son had diarrhea disease, I did not like the way I was handled, the way nurses were shouting at me and my son was so discouraging. They were blaming me for my son's illness, although they treated my son, I really felt bad and humiliated. I cannot advise any woman to go to that hospital again..." (FGD Discussant).

Majority 174 (74.7\%) of the respondents who had easy access to buildings and physical structures delivered at the hospital. There was a significant statistical association between ease of access to buildings and physical structures and choice of place of delivery $(\mathrm{p}=0.804)$. The results revealed that $189(81.1 \%)$ who had been given information delivered at the hospital. Further results showed a significant statistical association between being given information about services and choice of place of delivery among the respondents $(\mathrm{p}=0.001)$. Results were as presented on table 4.3.

Table 4.3: Health facility factors associated with choice of place of delivery among respondents $(n=411)$

\begin{tabular}{|c|c|c|c|c|}
\hline \multirow{2}{*}{ Independent variable } & \multirow{2}{*}{ Respondent response } & \multicolumn{2}{|c|}{ Choice of place of delivery } & \multirow{2}{*}{$\begin{array}{l}\text { Statistical } \\
\text { significance }\end{array}$} \\
\hline & & Home ( $N=178)$ & Hospital $(\mathrm{N}=\mathbf{2 3 3})$ & \\
\hline \multirow{3}{*}{$\begin{array}{l}\text { Approximate distance to the nearest } \\
\text { health facility }\end{array}$} & Less than $1 \mathrm{KM}$ & $40(22.5 \%)$ & $64(27.5 \%)$ & \multirow{3}{*}{$\begin{array}{c}\chi^{2}=50.489 \\
\mathrm{df}=2 \\
\mathrm{p}=0.001\end{array}$} \\
\hline & 2-3 KM & $61(34.2 \%)$ & $82(35.2 \%)$ & \\
\hline & Over $4 \mathrm{KM}$ & $77(43.3 \%)$ & $87(37.3 \%)$ & \\
\hline \multirow{5}{*}{$\begin{array}{c}\text { Cost of accessing antenatal care } \\
\text { services in Kshs }\end{array}$} & None/free & $49(27.5 \%)$ & $115(49.3 \%)$ & \multirow{5}{*}{$\begin{array}{c}\chi^{2}=7.623 \\
\mathrm{df}=4 \\
\mathrm{p}=0.053\end{array}$} \\
\hline & $1-99$ & $9(5.1 \%)$ & $16(6.9 \%)$ & \\
\hline & $100-199$ & $18(10.1 \%)$ & $23(9.9 \%)$ & \\
\hline & $200-299$ & $37(20.8 \%)$ & $37(15.9 \%)$ & \\
\hline & $\geq 300$ & $65(36.5 \%)$ & $42(18.0 \%)$ & \\
\hline \multirow{6}{*}{$\begin{array}{l}\text { Hindrances from delivery in health } \\
\text { facility }\end{array}$} & Lack equipment & $11(6.2 \%)$ & $48(20.6 \%)$ & \multirow{6}{*}{$\begin{array}{c}\chi^{2}=80.087 \\
\mathrm{df}=5 \\
\mathrm{p}=0.008\end{array}$} \\
\hline & Lack enough finances & $9(5.1 \%)$ & $24(10.3 \%)$ & \\
\hline & Poor provider attitude & $26(14.6 \%)$ & $16(6.9 \%)$ & \\
\hline & Poor quality services & $10(5.6 \%)$ & $23(9.9 \%)$ & \\
\hline & Distant health facility & $110(61.8 \%)$ & $60(25.7 \%)$ & \\
\hline & No hindrance & $12(6.7 \%)$ & $62(26.6 \%)$ & \\
\hline \multirow{3}{*}{$\begin{array}{l}\text { Experience with care providers during } \\
\text { service delivery }\end{array}$} & Good & $101(56.7 \%)$ & $137(58.8 \%)$ & \multirow{3}{*}{$\begin{array}{c}\chi^{2}=10.825 \\
\mathrm{df}=2 \\
\mathrm{p}=0.012\end{array}$} \\
\hline & Fair & $46(25.8 \%)$ & $69(29.6 \%)$ & \\
\hline & Poor & $31(17.4 \%)$ & $27(11.6 \%)$ & \\
\hline \multirow{2}{*}{$\begin{array}{l}\text { Easier to access buildings and } \\
\text { physical structures }\end{array}$} & Yes & $131(73.6 \%)$ & $174(74.7 \%)$ & \multirow{2}{*}{$\begin{array}{c}\chi^{2}=0.602 \\
\mathrm{df}=1 \\
\mathrm{p}=0.804\end{array}$} \\
\hline & No & $47(26.4 \%)$ & $59(25.3 \%)$ & \\
\hline \multirow{3}{*}{ Liked the quality of services received } & Yes & $161(90.4 \%)$ & $168(72.1 \%)$ & \multirow{3}{*}{$\begin{array}{c}\chi^{2}=21.267 \\
\mathrm{df}=1 \\
\mathrm{p}=0.091\end{array}$} \\
\hline & No & $17(9.6 \%)$ & $65(27.9 \%)$ & \\
\hline & No & $25(14.0 \%)$ & $46(19.7 \%)$ & \\
\hline \multirow{2}{*}{$\begin{array}{c}\text { Given information about antenatal } \\
\text { care services }\end{array}$} & Yes & $154(86.5 \%)$ & $189(81.1 \%)$ & \multirow{2}{*}{$\begin{array}{c}\chi^{2}=46.486 \\
\mathrm{df}=1 \\
\mathrm{p}=0.001\end{array}$} \\
\hline & No & $24(13.5 \%)$ & $44(18.9 \%)$ & \\
\hline
\end{tabular}




\section{DISCUSSIONS AND CONCLUSIONS}

\subsection{Discussions}

\subsubsection{Choice of place of delivery}

The study sought to establish the proportion of respondents who delivered at home and at the health facility respectively. The results showed that $56.7 \%$ of respondents delivered at the health facility. This shows a significant increase in facility based deliveries in the county as compared to previous rates which showed that health facility deliveries had stood at $44.4 \%$ in $2017^{32}$. This may be attributed to various interventions including mother pack incentives and existence of a working community based referral agents. The results were contrary to a study done among rural Indian women which showed that about a half $(50.0 \%)$ of pregnant women interviewed ended up delivering in health facilities ${ }^{15}$. In another study done in Guinea Bissau, it was reported that only $39.8 \%$ of deliveries occurred in hospital settings ${ }^{33}$. According to a comparative study done in rural Ghana, it was reported that $52.7 \%$ of women from the savanna zone delivered at home while $65.6 \%$ of women from the forest zone delivered at health facilities ${ }^{34}$.

According to this study results, instant labor pains was the main reason for occurrence of home deliveries. This was followed by successful previous deliveries occurred at home. This may be attributed to the fact that the health facilities were far distances apart and accessing them could be an issue especially if one experiences instant labor pains. The results were similar to a study done in rural Zambia where occurrence of shorter than expected labor pains prompted women to deliver at home ${ }^{35}$. According to another study that was done in Nigeria, it was noted that lack of husbands to give their wives consent hindered them from delivering at health facilities ${ }^{36}$. Contrary results were also reported by another study done in coastal Kenya among HIV/AIDS positive women who concluded that lack of good access to information was the main hindrance to deliver in health facilities ${ }^{37}$.

The study results also revealed that perceived quality of service provision was the main motivation for having their children born in health facilities. This means that they knew the dangers of home deliveries and believed in deliveries under the hands of skilled birth attendants to help minimize occurrence of complications. The results were contrary to a study done in Dodoma municipality in central Tanzania where nearness to the health facility was the main reason for hospital deliveries $^{38}$. In another study done in Zambia, inconsistent results were reported where fear of complications among pregnant women was the main driver for health facility deliveries $^{39}$. In a study done in Northwest Ethiopia it was noted that free availability of delivery services was the main reason for hospital deliveries ${ }^{40}$.

The study further sought to find out who assisted the respondents during delivery. The results revealed that $58.6 \%$ of the respondents were assisted by health care providers. This is probably because most of the deliveries occurred in health facilities hence attended by skilled birth attendants. However, still this was below the national average which stood at $62 \%$ skilled birth attendant deliveries ${ }^{1}$. The results were in agreement with a study done in Dodoma region of Tanzania where three quarters of child deliveries were conducted under the care of skilled birth attendants ${ }^{41}$. In a study in Guinea Bissau, it was reported that slightly more than a third of deliveries were conducted by skilled birth attendants ${ }^{33}$.

\subsubsection{Health facility factors and choice of place of delivery}

Results from health facility factors revealed that the respondents approximated the distance to the nearest health facility to be more than 4 kilometers. The results concur with a study done in Ghana in which showed that the average distance to the nearest health facility was 4.7 kilometers ${ }^{25}$. There was a significant statistical association between distance to the nearest facility and choice of place of delivery. Home deliveries increased with increase in distance to the nearest health facility. Long distances and poor road networks were associated with low hospital deliveries among pastoralist women in Kenya ${ }^{26}$. In another study done in Northwest Ethiopia, distance was among the factors that hindered women from delivering in health facilities ${ }^{24}$.

Majority of the respondents reported that the cost associated with health facility delivery was free. This could be attributed to the fact in Kenya due to introduction of Linda Mama Insurance Cover which guarantees free deliveries in public health facilities. The results were inconsistent with a study done in ethnic minority villages of Lao which revealed that it was extremely expensive to access hospital delivery services $^{27}$. There was no association between cost of accessing delivery services and choice of place of delivery. According to other studies, they concluded that women deliver at home to avoid the costs incurred in hospital delivery ${ }^{26}$. The indirect costs associated with hospital deliveries in remote areas of Sierra Leone were high hence opting for home deliveries ${ }^{21}$.

Most of the respondents had a good experience with care providers during service delivery. Good handling of patients means they can seek subsequent services in the health facilities thus more hospital deliveries. Mistreatment of women during delivery has been noted as factor that affected hospital delivery among pregnant women in Nigeria ${ }^{17}$. Experience with health services providers significantly influenced choice of place of delivery. Healthcare providers criticize and provide fragmented care during pregnancy and child birth $^{42}$.

The findings of this study there was ease of access to buildings and physical structures as reported by majority of respondents. There was a significant statistical association between ease of access to buildings and physical structures and choice of place of delivery. Friendly structures coupled organized channels of service delivery means pregnant women can easily access services without struggles. The results concur with a study done in Northwest Ethiopia where it was reported that existence ease of access to hospital 
infrastructure was significantly associated with hospital deliveries $^{28}$. Good physical accessibility of services influenced choice of place of delivery among women from ethnic minority villages in $\mathrm{Lao}^{27}$.

The study further revealed that most of the respondents liked the reception they received from health care providers. Poor handling of clients may make them shy off from making subsequent visits to the health facilities. There was a significant statistical association between liking the reception one got at the facility and choice of place of delivery. Perceived potential behavior and reception from the healthcare staff was an issue in Serra Leone that significantly influenced hospital delivery ${ }^{21}$. Perceived support from care providers during service delivery improves maternal as most women would cooperate and deliver in health facilities ${ }^{20}$. In a qualitative study done in Tanzania, most people preferred to deliver at private hospitals and/or at home because they reported bad reception at government facilities ${ }^{22}$.

Perceived quality of service delivery especially among pregnant women has been noted to be a significant determinant of choice of place of delivery. However, in this study there was no statistically significant association between liking the quality of services one received and choice of place of delivery. This may be because they had already been admitted to deliver in the facilities hence this could only affect their subsequent visits. Choosing to deliver at home is associated with concerns about the quality of services prompting women to shy from hospital facilities ${ }^{16}$. The patients' perception concerning the quality of service provision is very important since it influences their health outcomes. Provision of services which meet the needs, wishes and expectations of women leads to high hospital deliveries ${ }^{14}$.

Further, the results showed that most of the respondents were given information before and after services. People have reported lack of provision of the right information thus persisted practice of home deliveries ${ }^{26}$. There was a significant statistical association between being given information before and after service and choice of place of delivery. Information empowers women to make informed decisions on the most appropriate place of delivery. Provision of information to pregnant women has been associated to great impact the choice of place of delivery ${ }^{18}$.

\subsection{Conclusions}

The study concluded that there was a significant number of women who are still delivering at home in Marsabit County. Majority of the health system factors were associated with choice of place of delivery. This requires concerted efforts by relevant stakeholders to ensure improved access health facility delivery through mobile clinics to assist women deliver under the hands of skilled birth attendants thus discouraging home deliveries.

\section{ACKNOWLEDGEMENT}

We would like to acknowledge the Almighty Father for giving us good health, source of knowledge and wisdom. Special appreciation to our research assistants, our families and colleagues for immense moral support during the course of this study. God bless you all.

\section{REFERENCES}

[1] WHO, UNICEF, UNFPA, World Bank Group, and the United Nations Population Division. (2019). Trends in Maternal Mortality: 2000 to 2017. Geneva, World Health Organization.

[2] Kenya National Bureau of Statistics. (2014). Kenya Demographic and health Survey 2014. Rockville, Maryland.

[3] Moindi, R., Ngari, M,, Nyambati, V. and Mbakaya, C. (2016). Why mothers still deliver at home: understanding factors associated with home deliveries and cultural practices in rural coastal Kenya, a cross-section study. BMC Public Health. 2016; 16: 114.

[4] Republic of Kenya (2015). Status of implementation of free maternity services (FMS) program in the devolved health system in Kenya. Nairobi: Ministry of Health; 2015.

[5] Njuki, R., Abuya, T., Kimani, J., Kanya, L, Korongo, A., Mukanya, C. (2015). Does a voucher program improve reproductive health service delivery and access in Kenya? BMC Health Serv Res. 15:206

[6] Mulinge Mutinda (2017). Factors influencing unskilled delivery in Kenya. Nairobi, University of Nairobi.

[7] Orit, A, Erika, L, Halima M, Fetene, N. and Bradley, E. (2015). A patient-centred understanding of the referral system in Ethiopian primary healthcare units. PLoS One, 10(10):1-10.

[8] World Health Organization. (2018). Trends in Maternal Mortality: 1990-2015 Estimates by WHO, UNFPA, UNICEF. The World Bank and the United Nations Population Division. Geneva: World Health Organization.

[9] Alkema L, Chou D., Hogan D., Zhang S., Moller, A.B., Gemmill, A. (2015). Global, regional, and national levels and trends in maternal mortality between 1990 and 2015, with scenario-based projections to 2030: a systematic analysis by the UN Maternal Mortality Estimation Inter-Agency Group. Lancet. 2016; 387 (10017): 462-74

[10] UNDP (2015). Sustainable Development Goals. New York: NY, UNDP

[11] Federal Ministry of Health, Health and Health Related Indicators. (2011). Policy Planning Directorate, Addis Ababa, Ethiopia.

[12] Ashimi, A. O., \& Amole, T. G. (2015). Prevalence, reasons and predictors for home births among pregnant women attending antenatal care in Birnin Kudu, North-west Nigeria. Sexual \& Reproductive Healthcare, 6(3), 119-125.

[13] Chama-Chiliba, C. M., \& Koch, S. F. (2016). An assessment of the effect of user fee policy reform on facility-based deliveries in rural Zambia. BMC Research Notes, 9(1), 1-14.

[14] Ngugi, A. K., Agoi, F., Mahoney, M. R., Lakhani, A., Mang'ong'o, D., Nderitu, E., \& Macfarlane, S. (2017). Utilization of health services in a resource-limited rural area in Kenya: prevalence and associated household-level factors. PloS one, 12(2), e0172728.

[15] Gorain, A., Barik, A., Chowdhury, A. and Rai, R. K. (2017), Preference in place of delivery among rural Indian women. Plos one, 12(12), e0190117.

[16] Sudhinaraset, M., Beyeler, N., Barge, S. and Diamond-Smith, N. (2016). Decision-making for delivery location and quality of care among slum-dwellers: a qualitative study in Uttar Pradesh, India. BMC pregnancy and childbirth, 16(1), 1-10.

[17] Bohren, M. A., Vogel, J. P., Tunçalp, Ö., Fawole, B., Titiloye, M. A., Olutayo, A. O. and Hindin, M. J. (2017). Mistreatment of women during childbirth in Abuja, Nigeria: a qualitative study on perceptions and experiences of women and healthcare providers. Reproductive health, 14(1), 1-13. 
[18] Kamali, S., Ahmadian, L., Khajouei, R. and Bahaadinbeigy, K. (2018). Health information needs of pregnant women: information sources, motives and barriers. Health Information \& Libraries Journal, 35(1), 24-37.

[19] Ogolla, J. O. (2015). Factors associated with home delivery in West Pokot County of Kenya. Advances in public health

[20] Chityaka, F., \& Ngoma, C. M. (2018). Factors influencing decisions to homebirth among pregnant women in Mpongwe District, Zambia. African Journal of Midwifery and Women's Health, 12(2), 73-76.

[21] Treacy, L., Bolkan, H. A. and Sagbakken, M. (2018). Distance, accessibility and costs. Decision-making during childbirth in rural Sierra Leone: a qualitative study. PLoS One, 13(2), e0188280.

[22] Kohi, T. W., Mselle, L. T., Dol, J. and Aston, M. (2018). When, where and who? Accessing health facility delivery care from the perspective of women and men in Tanzania: a qualitative study. BMC health services research, 18(1), 1-9.

[23] Otieno J. O. (2015). Factors Associated with Home Delivery in West Pokot County of Kenya. Advances in Public Health, vol. 2015, Article ID 493184, 6 pages.

[24] Kidanu, S., Degu, G. and Tiruye, T. Y. (2017). Factors influencing institutional delivery service utilization in Dembecha district, Northwest Ethiopia: a community based cross sectional study. Reproductive health, 14(1), 1-8.

[25] Dotse-Gborgbortsi, W., Dwomoh, D., Alegana, V., Hill, A., Tatem, A. J. and Wright, J. (2020). The influence of distance and quality on utilisation of birthing services at health facilities in Eastern Region, Ghana. BMJ global health, 4(Suppl 5)

[26] Caulfield, T., Onyo, P., Byrne, A., Nduba, J., Nyagero, J., Morgan, A. and Kermode, M. (2016). Factors influencing place of delivery for pastoralist women in Kenya: a qualitative study. BMC women's health, 16(1), 1-11.

[27] Sato, C., Phongluxa, K., Toyama, N., Gregorio, E. R., Miyoshi, C., Nishimoto, F. and Kobayashi, J. (2019). Factors influencing the choice of facility-based delivery in the ethnic minority villages of Lao PDR: a qualitative case study. Tropical medicine and health, 47(1), 1-11.

[28] Gashaye, K. T., Tsegaye, A. T., Shiferaw, G., Worku, A. G. and Abebe, S. M. (2019). Client satisfaction with existing labor and delivery care and associated factors among mothers who gave birth in university of Gondar teaching hospital; Northwest Ethiopia: institution based cross-sectional study. PLoS One, 14(2), e0210693.

[29] Kenya National Bureau of statistics. (2019). Kenya National Population and Housing Census 2019. Rockville, Maryland.

[30] Ministry of Health (2015). Marsabit County Health at a Glance. Nairobi, Ministry of Health
[31] Fishers and Fowler, F. J. (1998). Survey research methods (2nd ed.). Los Angeles: Sage Publications.

[32] Ministry of Health (2018). Marsabit County maternal, infant and young children nutrition knowledge attitude and practices baseline survey report. Nairobi, Government printer.

[33] Yaya, S., Bishwajit, G. and Gunawardena, N. (2019). Socioeconomic factors associated with choice of delivery place among mothers: a population-based cross-sectional study in Guinea-Bissau. BMJ global health, 4(2), e001341.

[34] Dickson, K. S., Adde, K. S. and Amu, H. (2016). What influences where they give birth? Determinants of place of delivery among women in rural Ghana. International journal of reproductive medicine, 2016.

[35] Scott, N. A., Henry, E. G., Kaiser, J. L., Mataka, K., Rockers, P. C., Fong, R. M. and Lori, J. R. (2018). Factors affecting home delivery among women living in remote areas of rural Zambia: a cross-sectional, mixed-methods analysis. International journal of women's health, 10, 589.

[36] Shehu, C. E., Ibrahim, M. T. O., Oche, M. O. and Nwobodo, E. I. (2016). Determinants of place of delivery: a comparison between an urban and a rural community in Nigeria. Journal of Public Health and Epidemiology, 8(6), 91-101.

[37] Chea, S. K., Mwangi, T. W., Ndirangu, K. K., Abdullahi, O. A., Munywoki, P. K., Abubakar, A., and Hassan, A. S. (2018). Prevalence and correlates of home delivery amongst HIV-infected women attending care at a rural public health facility in Coastal Kenya. PLoS One, 13(3), e0194028.

[38] Muhunzi, S., Ngocho, J. S., Mwanamsangu, A., Sanga, L., Hiza, H., Msuya, S. E. and Mahande, M. J. (2020). Prevalence, predictors and reasons for home delivery amongst women of childbearing age in Dodoma Municipality in central Tanzania. African Health Sciences, 20(4), 1933-42.

[39] Sialubanje, C., Massar, K., Hamer, D. H. and Ruiter, R. A. (2015). Reasons for home delivery and use of traditional birth attendants in rural Zambia: a qualitative study. BMC pregnancy and childbirth, 15(1), 1-12.

[40] Nigatu, A. M., Gelaye, K. A. (2019). Factors associated with the preference of institutional delivery after antenatal care attendance in Northwest Ethiopia. BMC health services research, 19(1), 1-9.

[41] Ngowi, A. F., Kamazima, S. R., Kibusi, S., Gesase, A. and Bali, T. (2017). Women's determinant factors for preferred place of delivery in Dodoma region Tanzania: a cross sectional study. Reproductive health, 14(1), 1-8.

[42] Altman M. R., Oseguera, T., McLemore, M. R., KantrowitzGordon, I., Franck, L. S. and Lyndon, A. (2019). Information and power: women of color's experiences interacting with health care providers in pregnancy and birth. Social science \& medicine, 238, 112491. 